\section{The Adsorption of Gold on Activated Carbon from Thiosulfate- Ammoniacal Solutions}

\author{
P Navarro ${ }^{\mathrm{a}}$, C Vargas $^{\mathrm{a}}, \mathrm{M}^{\text {Alonso }}{ }^{\mathrm{b}}$, \\ FJ Alguacil ${ }^{b}$ \\ a Departamento de Ingeniería Metalúrgica, \\ Universidad de Santiago de Chile, Avda. L. B. O'Higgins \\ 3363, Casilla 10233, Santiago, Chile. \\ E-mail: pnavarro@lauca.usach.cl \\ ${ }^{\mathrm{b}}$ Centro Nacional de Investigaciones Metalúrgicas \\ (CSIC), Avda. Gregorio del Amo 8, Ciudad Universitaria, \\ 28040 Madrid, Spain. E-mail: fjalgua@cenim.csic.es
}

\begin{abstract}
The adsorption of gold on activated carbon in ammoniacal thiosulfate solution was studied. The variables affecting the adsorption of gold on the carbon included, among others, temperature, concentrations of ammonium hydroxide and thiosulfate, and those of accompanying cations and anions. The apparent activation energy for the adsorption process was estimated to be $19.4 \mathrm{~kJ} / \mathrm{mol}$, and this value indicates that the gold adsorption is film diffusion-controlled. It was also found that the rate of initial adsorption rate was fast, when compared to that of the overall adsorption process.
\end{abstract}

\section{Keywords}

thiosulfate, ammonia, activated carbon, gold

\section{Introduction}

Hydrometallurgical processing can be effectively used for the treatment of gold-bearing raw materials. Cyanidation is currently the main choice for the extraction of gold from ores. However, the toxicity of cyanide and the failure of this complexant to extract gold from the so-called difficult to treat raw materials (e.g. carbonaceous and copper-gold ores) led to the investigation of alternatives for gold extraction from various resources.

Chloride, thiosulfate, sulphide, ammonia and sulfite have been identified as low cost alternatives, the first two being more beneficial in terms of health and safety issues and low environmental impact. Among the above complexing agents, thiosulfate is of considerable interest, because it can be used for leaching of gold from carbonaceous gold ores as gold-thiosulfate complex which is not preg-robbed by the carbonaceous component of the ores [1,2]. The gold leaching reaction with thiosulfate can be described, in its simplified form, by the following reaction:

$$
2 \mathrm{Au}+4 \mathrm{~S}_{2} \mathrm{O}_{3}^{2-}+\frac{1}{2} \mathrm{O}_{2}+\mathrm{H}_{2} \mathrm{O} \rightarrow 2 \mathrm{Au}\left(\mathrm{S}_{2} \mathrm{O}_{3}\right)_{2}^{3-}+2 \mathrm{OH}^{-}
$$

To accelerate this reaction, catalytically, ammonium hydroxide and copper (II) are commonly added:

$$
\mathrm{Au}+5 \mathrm{~S}_{2} \mathrm{O}_{3}^{2-}+\mathrm{Cu}\left(\mathrm{NH}_{3}\right)_{4}^{2+} \rightarrow \mathrm{Au}\left(\mathrm{S}_{2} \mathrm{O}_{3}\right)_{2}^{3-}+4 \mathrm{NH}_{3}+\mathrm{Cu}\left(\mathrm{S}_{2} \mathrm{O}_{3}\right)_{3}^{5-}
$$

The formation of cuprous thiosulfate complex in the above reaction consumes the thiosulfate and retards the gold leaching. Thus, the cuprous complex should be oxidized back to cupric ammine complex as much as possible:

$$
\begin{array}{r}
4 \mathrm{Cu}\left(\mathrm{S}_{2} \mathrm{O}_{3}\right)_{3}^{5-}+16 \mathrm{NH}_{3}+\mathrm{O}_{2}+2 \mathrm{H}_{2} \mathrm{O} \rightarrow \\
4 \mathrm{Cu}\left(\mathrm{NH}_{3}\right)_{4}^{2+}+12 \mathrm{~S}_{2} \mathrm{O}_{3}^{2-}+4 \mathrm{OH}^{-}
\end{array}
$$

Combining Eqs. (2) and (3) results in the overall gold dissolution reaction in thiosulfate solution (Eq.(1)).

Once gold is dissolved, the recovery of gold from the pregnant thiosulfate solutions can be carried out by different procedures e.g. adsorption, solvent extraction, etc. [1,3-7].

Though adsorption on activated carbon is one of the common procedures used in the recovery of gold from cyanide solutions [8], it has not been used widely for the processing of gold-thiosulfate solutions, several reasons for this situation are described in the literature [9].

In this paper, the results of an investigation on the application of this technology to the adsorption of gold from ammoniacal thiosulfate solutions are reported.

\section{Experimental}

The gold thiosulfate complex used in this investigation was obtained from Alfaaesar, a stock gold solution was prepared 
Table 1

Characteristics of the activated carbon

\begin{tabular}{lc}
$\frac{\text { Length (cylinder) }}{\text { Diameter (cylinder) }}$ & $5.6 \mathrm{~mm}$ \\
\hline Surface area & $3 \mathrm{~mm}$ \\
\hline Micropores & $925 \mathrm{~m}^{2} / \mathrm{g}$ \\
\hline
\end{tabular}

by dissolution of the reagent in distilled water. Each working gold solution was prepared by mixing a known quantity of the stock solution with an appropriate amount of ammonium hydroxide solution. All other chemicals were of reagent grade.

The activated coconut-shell carbon, obtained from Anglo Chilena SA, was washed with deionized water, dried at $60^{\circ} \mathrm{C}$ for $48 \mathrm{~h}$ and stored in a desiccator under vaccum. Table 1 lists main physical characteristics of the activated carbon.

Gold adsorption tests were carried out in a $1000 \mathrm{ml}$ glass reactor equipped with a stirring device. The reactor was placed in a constant temperature water bath. Experiments were run at a stirring speed of $500 \mathrm{~min}^{-1}$ with $500 \mathrm{ml}$ of the gold solution. When the $\mathrm{pH}$ of the solution was properly adjusted and the desired temperature was reached, the experiments were initiated by placing a weighed amount of the activated carbon into the reactor. Samples were periodically taken for chemical analysis by AAS. The effectiveness of the adsorption process was estimated from the percentage of gold adsorption, which was calculated by using the following equation:

$$
A=\frac{\left(C_{0}-C_{t}\right)}{C_{0}} \cdot 100
$$

where $C_{0}$ is the initial gold concentration and $C_{t}$ is the concentration at an elapsed time, $t$, after the addition of active carbon.

\section{Results and discussion}

\section{Effect of ammonium hydroxide}

Experiments were carried out at three different concentrations of ammonium hydroxide, namely 0.3, 0.6 and $1 \mathrm{~mol} / \mathrm{l}$. The aqueous solution had the initial concentrations of $10 \mathrm{mg} / \mathrm{l}$ for gold and $1.02 \times 10^{-4} \mathrm{M}$ for thiosulfate. The results of these experiments (Table 2) show that at shorter times, the adsorption of gold on the carbon increased with increasing ammonium hydroxide concentration up to $0.6 \mathrm{~mol} / \mathrm{l}$ and then remained constant,

\section{Table 2}

The adsorption of gold on activated carbon as a function of various $\mathrm{NH}_{4} \mathrm{OH}$ concentrations

\begin{tabular}{|c|c|c|}
\hline $\mathrm{NH}_{4} \mathrm{OH}, \mathrm{mol} / \mathrm{l}$ & $\begin{array}{l}\text { Gold } \\
\text { adsorption (1 h) }\end{array}$ & $\begin{array}{l}\text { Gold } \\
\text { adsorption }(8 \mathrm{~h})\end{array}$ \\
\hline 0.3 & $23.6 \%$ & $53.8 \%$ \\
\hline 0.6 & $32.8 \%$ & $55.4 \%$ \\
\hline 1.0 & $32.5 \%$ & $55.5 \%$ \\
\hline
\end{tabular}

pH 9.5. Temperature: $20^{\circ} \mathrm{C}$. Added activated carbon: $0.3 \mathrm{~g}$
Table 3

Influence of $\mathrm{pH}$ on gold adsorption

\begin{tabular}{|c|c|c|}
\hline $\mathrm{pH}$ & $\begin{array}{l}\text { Gold } \\
\text { adsorption (1 h) }\end{array}$ & $\begin{array}{l}\text { Gold } \\
\text { adsorption }(8 \mathrm{~h})\end{array}$ \\
\hline 8.5 & $11.3 \%$ & $26.0 \%$ \\
\hline 9.5 & $18.5 \%$ & $29.5 \%$ \\
\hline 10.5 & $31.2 \%$ & $55.4 \%$ \\
\hline 11.0 & $4.4 \%$ & $23.3 \%$ \\
\hline
\end{tabular}

Aqueous solution: $10 \mathrm{mg} / \mathrm{Au}, 1.02 \times 10^{-4} \mathrm{M}$ thiosulfate, $1 \mathrm{M} \mathrm{NH}_{4} \mathrm{OH}$. Temperature: $20^{\circ} \mathrm{C}$. Added activated carbon: $0.3 \mathrm{~g}$

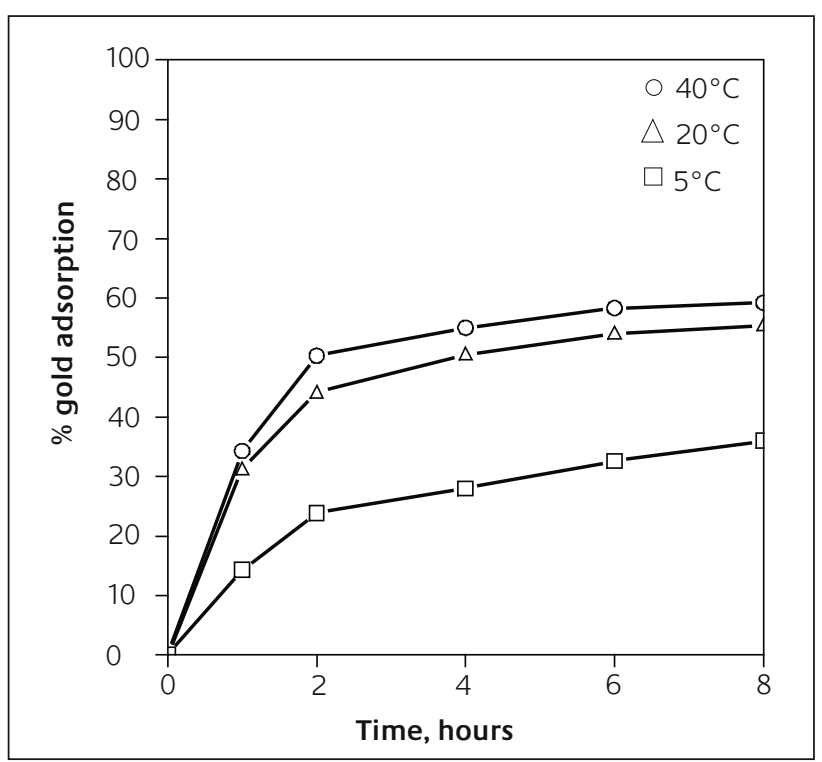

Figure 1

The percentage of gold adsorbed on activated carbon at various temperatures

while the effect of ammonium hydroxide concentration was less significant at longer reaction times, at which the percentage of gold adsorbed onto the carbon is practically the same at the three different ammonium hydroxide concentrations used.

Though not shown in this paper, a further increase in ammonium hydroxide concentration led to a decrease in the adsorption of gold on the carbon. This result may be attributed to the competitive adsorption of ammonium ion with gold ion on the carbon surface, i.e., an increase in ammonium hydroxide concentration results in a decrease in activity and diffusivity of gold ion, leading to a decrease in gold adsorption [10].

\section{Effect of $\mathrm{pH}$}

Previous investigations on gold leaching confirmed that a $\mathrm{pH}$ value of near 9.5 was optimal for gold extraction $[1,2,11]$; therefore, the effect of $\mathrm{pH}$ on gold adsorption was studied in this range. As can be seen from the results shown in Table 3, the $\mathrm{pH}$ variation did affect the gold adsorption, i.e., it was severely retarded at the lower and higher $\mathrm{pH}$ values, with an optimum gold adsorption taking place at the $\mathrm{pH}$ of 10.5 .

Generally speaking the adsorption rate of gold on activated carbon is relatively fast during the initial stage if 
Table 4

Effect of different anions on the adsorption of gold on carbon

\section{Anion}

$\%$ Gold adsorption ${ }^{\mathrm{a}}$

\begin{tabular}{ll}
$\frac{\mathrm{S}_{2} \mathrm{O}_{3}{ }^{2-}\left(1.02 \times 10^{-4} \mathrm{M}\right)}{\mathrm{S}_{2} \mathrm{O}_{3}{ }^{2-}(0.2 \mathrm{M})}$ & 55.4 \\
\hline$\frac{\mathrm{Cl}^{-}(0.5 \mathrm{M})}{\mathrm{ClO}_{4}-(0.5 \mathrm{M})}$ & 13.2 \\
\hline & 41.0 \\
\hline After 8 h. Other experimental conditions were the same as for Figure 2
\end{tabular}

Other experimental conditions were the same as for Figure 2

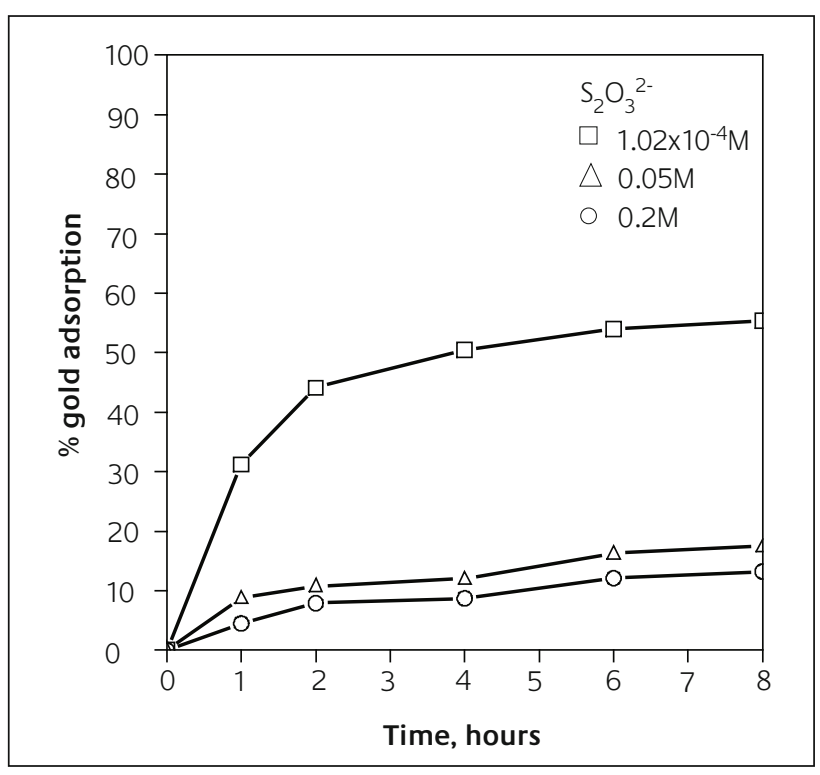

\section{Figure 2}

The percentage of gold adsorbed on activated carbon at various thiosulfate concentrations. Aqueous phase: $10 \mathrm{mg} / \mathrm{l}$ gold, $0.8 \mathrm{M} \mathrm{NH}_{4} \mathrm{OH}$ and various thiosulfate concentrations at $\mathrm{pH}$ 10.5. Added activated carbon: $0.3 \mathrm{~g}$. Temperature: $20^{\circ} \mathrm{C}$

compared to that of the overall adsorption process. This is attributable to the quick adsorption of gold on macropores of activated carbon and the slow diffusion of gold into micropores, which comprises a large percentage (96\%) of the total pore volume of the carbon.

\section{Effect of temperature}

To investigate the influence of temperature on the adsorption of gold on activated carbon, experiments were carried out at 5,20 and $40^{\circ} \mathrm{C}$. The initial concentration of gold was $10 \mathrm{mg} / \mathrm{l}$, the thiosulfate concentration was $1.02 \times 10^{-4} \mathrm{M}$ and the ammonium hydroxide concentration was $0.8 \mathrm{M}$. The $\mathrm{pH}$ of the aqueous phase was 10.5, and $0.3 \mathrm{~g}$ of activated carbon was added to the gold solution. Figure 1 shows the effect of temperature on the adsorption of gold. It is seen that, within the range of temperature investigated, the adsorption of gold on activated carbon increased with increasing temperature. The activation energy was estimated as $19.4 \mathrm{~kJ} / \mathrm{mol}$. This value supports the contention that the gold adsorption proceeds via a film diffusion-controlled mechanism [6, 12-14].

\section{Effect of thiosulfate and different anions}

Figure 2 plots the percentage of gold adsorption vs time for experiments performed with various initial thiosulfate concentrations. It can be seen that the presence of this anion in

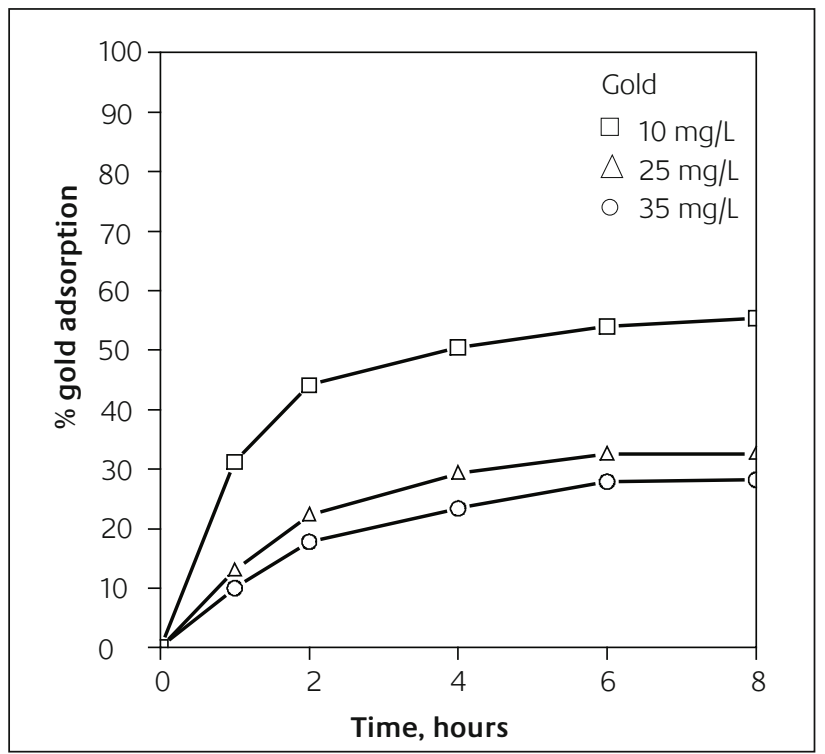

\section{Figure 3}

The percentage of gold absorbed on activated carbon as a function of initial gold concentration in solution. Aqueous phase: various gold concentrations and $0.8 \mathrm{M} \mathrm{NH}_{4} \mathrm{OH}$ at $\mathrm{pH}$ 10.5. Added activated carbon: 0.3g. Temperature: $20^{\circ} \mathrm{C}$

the aqueous solution influences the adsorption of gold onto the activated carbon. Two effects can be seen: first, the adsorption rate increases with increasing initial thiosulfate concentration, and second, the percentage of gold adsorbed during a given length of time decreases with increasing thiosulfate concentration. This is a serious drawback because practical leachings are expected to contain an excess of thiosulfate.

The decrease in gold adsorption is probably caused by side reactions which affect the overall gold adsorption process, e.g., excess thiosulfate ions can undergo the following disproportionation reactions $[4,5]$ :

$$
\begin{gathered}
\mathrm{S}_{2} \mathrm{O}_{3}^{2} \Leftrightarrow \mathrm{S}^{0}+\mathrm{SO}_{3}^{2-} \\
3 \mathrm{~S}_{2} \mathrm{O}_{3}^{2-}+\mathrm{H}_{2} \mathrm{O} \Leftrightarrow 2 \mathrm{SO}_{4}^{2-}+4 \mathrm{~S}^{0}+2 \mathrm{OH}^{-}
\end{gathered}
$$

The precipitated sulphur may decrease the surface area available for gold adsorption. In addition, the probable decomposition of thiosulfate into tetrathionate $\left(\mathrm{S}_{4} \mathrm{O}_{6}{ }^{2-}\right)$ and trithionate $\left(\mathrm{S}_{3} \mathrm{O}_{6}{ }^{2-}\right)$ and the detrimental effect of these species may also result in a decrease in gold adsorption.

Furthermore, the influence of various anions on the adsorption of gold was investigated by adding individually those anions into the gold solution as the corresponding sodium salt. Table 4 summarizes the observed effects of thiosulfate, chloride and perchlorate ions on the adsorption of gold on the carbon. It can be seen that the presence of these anions caused a decrease in gold recovery. The decrease in gold adsorption in the presence of these anions is also attributable to a decreased diffusivity of gold species caused by the anions [15].

Though not investigated in the present work, it is known that the addition of cyanide ions in the system has a positive influence, increasing the adsorption of gold onto the carbon [1]. 


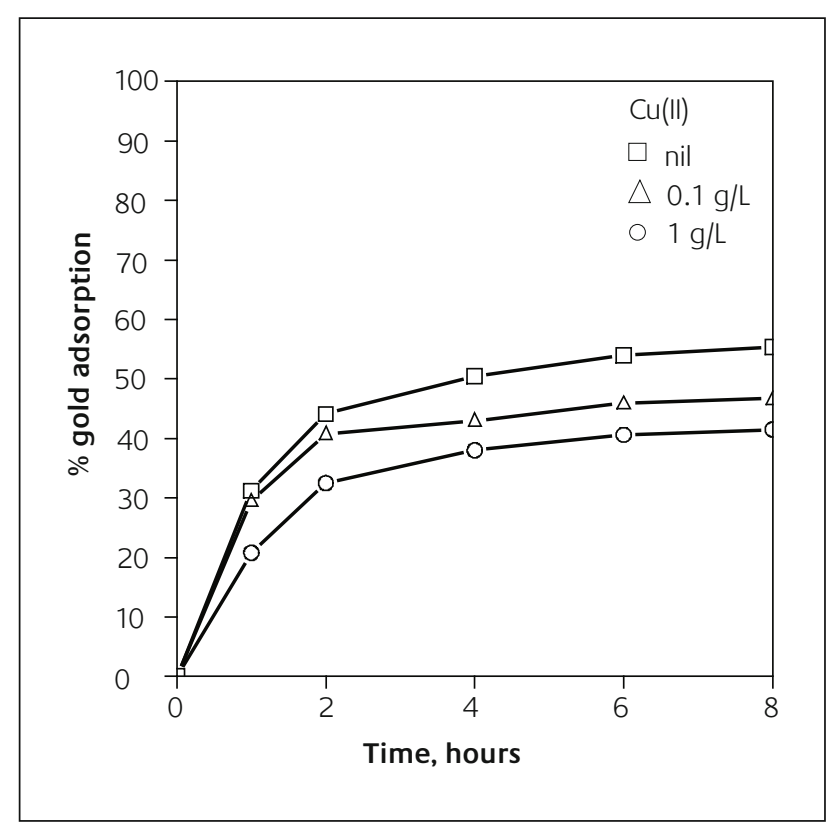

\section{Figure 4}

The percentage of gold adsorbed on activated carbon in the presence of copper (II) in the solution. Aqueous phase: $10 \mathrm{mg} / \mathrm{lg}$ gold, $1.02 \times 10^{-4} \mathrm{M}$ thiosulfate, $0.8 \mathrm{M} \mathrm{NH}_{4} \mathrm{OH}$ and copper (II) at $\mathrm{pH}$ 10.5. Added activated carbon: $0.3 \mathrm{~g}$. Temperature: $20^{\circ} \mathrm{C}$

\section{Effect of gold concentration}

As can be seen from Figure 3, the initial gold concentration has a significant influence on the adsorption of gold. It is clear that the higher the initial concentration of gold, the lower the adsorption rate. Moreover, the percentage of gold adsorbed onto the carbon increased as the initial gold concentration was decreased. This result can be understood by assuming that the available active sites are insufficient to increase gold loading proportionately to the increase of gold in the initial aqueous solution, and thus decreasing the percentage of gold adsorption onto the carbon.

\section{Influence of copper (and zinc)}

As described already, the role of copper in the dissolution of gold in ammoniacal thiosulfate solutions is very important. Thus, it seemed appropriate to determine the influence of this metal, normally present as $\mathrm{Cu}\left(\mathrm{NH}_{3}\right)_{4}{ }^{2+}$ complex, on the adsorption of gold. This was determined at various concentrations of copper (0-1 g/l).

As can be seen from Figure 4, the presence of copper in solution in the form of the above complex affects the adsorption of gold onto the carbon. As the concentration of copper was increased, the percentage of the gold recovered became less. One probable explanation for this behaviour is the co-adsorption of copper with gold (e.g. at the initial $\mathrm{Cu}(\mathrm{II})$ concentration of $0.1 \mathrm{~g} / \mathrm{l}, 10.7 \%$ of this metal was adsorbed onto the carbon after $8 \mathrm{~h}$ ).

Zinc can also be present in the raw material, and thus, it can be found in the gold leaching solution. Its influence on gold

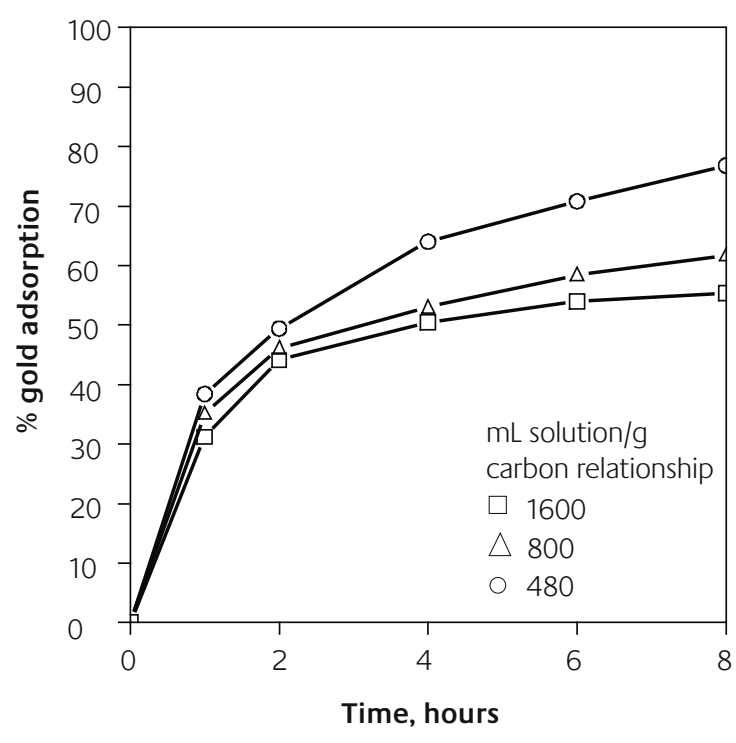

Figure 5

The percentage of gold adsorbed on activated carbon with various amounts of activated carbon. Aqueous phase: $10 \mathrm{mg} / \mathrm{L}$ gold, $1.02 \times 10^{-4}$ $\mathrm{M}$ thiosulfate, $0.8 \mathrm{M} \mathrm{NH}_{4} \mathrm{OH}$ at $\mathrm{pH} 10.5$. Temperature: $20^{\circ} \mathrm{C}$

adsorption was also investigated. The presence of zinc in the gold solution, though full data are not presented in this paper, showed an effect similar to that of copper; e.g., the percentage gold recovery found in the absence of zinc was equal to $54.0 \%$, while in the presence of 0.1 and $1 \mathrm{~g} / \mathrm{l}$ zinc, the recovery percentages were $48.7 \%$ and $34.8 \%$, respectively after 6 h of adsorption time. All other experimental conditions were identical to those for Figure 4.

\section{Effect of the amount of activated carbon}

Experiments were carried out using various amounts of carbon to examine its effect on both the percentage of gold adsorbed and on the adsorption rate. Experimental results obtained by varying the ratio of the volume of solution to the amount of added carbon from 1600 to $480 \mathrm{ml}$ of solution/g of carbon are shown in Figure 5. It is seen that the recovery of gold increases with a decrease in the above ratio, while the adsorption rate is only slightly affected by the variation of the amount of carbon added to the solution. It can be deduced that the surface area of the carbon plays an important role in the adsorption, because the more carbon used, the greater the surface area. Typical metal loadings of the carbon after the reaction time of $8 \mathrm{~h}$ were found to be 7.0, 4.6 and 3.4 $\mathrm{g} / \mathrm{kg}$ carbon, respectively for the solution volume to weight of carbon ratios of 1600, 800 and 480 (ml solution/g carbon), respectively.

The authors wish to acknowledge CONICYT (Chile) for project FONDECYT 7040009 and also wish to thank CSIC (Spain) and USACH (Chile) for project 2003CL0001. 


\section{About the authors}

P Navarro (Professor) and C Vargas (Adjuntant Professor) are within the staff of the Department of Metallurgical Engineering of the Universidad of Santiago de Chile, their investigations include the hydrometallurgical processing of raw materials. M Alonso (Scientific Tenure) and FJ Alguacil (Professor) are within the staff of the High Council of Scientific Research (CSIC) of the Spanish Government, their investigations include, besides aerosol sciences and environmental sciences, the hydrometallurgical processing of raw materials.

\section{References}

1 M.G. Aylmore, D.M. Muir, Min. Eng., 2001, 14, 135 and references therein

2 P. Navarro, C. Vargas, A. Villarroel, F.J. Alguacil, Hydrometallurgy, $2002,65,37$
3 H. Zhang, D. Dreisinger, Hydrometallurgy, 2002, 66, 67 and references therein

4 A.C. Grosse, G.W. Dicinoski, M.J. Shaw, P.R. Haddad, Hydrometallurgy, 2003, 69, 1 and references therein

5 J.B. Hiskey, J. Lee, Hydrometallurgy, 2003, 69, 45

6 P. Navarro, R. Alvarez, C. Vargas, F.J. Alguacil, Min. Eng., 2004, 17,825

7 H. Zhang, D.B. Dreisinger, Hydrometallurgy, 2004, 72, 225

8 J. Marsden, I. House, The Chemistry of Gold Extraction, Ellis Horwood, Chichester, 1992

9 N.P. Gallagher, J.L. Hendrix, E.B. Milosavljevic, J.H. Nelson, L. Solujic, Hydrometallurgy, 1990, 305

10 Q. Xu, X. Meng, K.N. Han, Min. \& Met. Proc., 1996, November, 141

11 H. Arima, T. Fujita, W.T. Yen, Min. \& Metal. Proc., 2003, 20, 81

12 R.H. Perry, D. Green, Perry's Chemical Engineers' Handbook, McGraw-Hill, New York, 1984

13 F.J. Alguacil, M. Alonso, L.J. Lozano, Chemosphere, 2004, 57, 789

14 P. Navarro, C. Vargas, F.J. Alguacil, Rev. Metal. Madrid, 2005, 41, 107

15 T. Rubcumintara, K.N. Han, Met. Trans. B, 21B, 429 